\title{
What do Parents Know About Oral Health and Care for Preschool Children in the Central Region of Saudi Arabia?
}

\author{
Sanaa N. Al-Haj Ali1 ${ }^{\circledR}$, Sondos H. Alshabaan²
}

${ }^{1}$ Department of Orthodontics and Pediatric Dentistry, College of Dentistry, Qassim University, Qassim, Saudi Arabia.

${ }^{2}$ College of Dentistry, Qassim University, Qassim, Saudi Arabia.

Author to whom correspondence should be addressed: Sanaa N. Al-Haj Ali, Department of Orthodontics and Pediatric Dentistry, College of Dentistry, Qassim University, Qassim, Saudi Arabia, PO Box: 6700. Postal Code: 51452. Phone: 00966504603339.E-mail:dr.sanaa.alhajali@qudent.org

Academic Editor: Burak Buldur

Received: 21 May 2020 / Review: 16 June 2020 / Accepted: 26 June 2020

How to cite this article: Al-Haj Ali SN, Alshabaan SH. What do parents know about oral health and care for preschool children in the central region of Saudi Arabia?. Pesqui Bras Odontopediatria Clín Integr. 2020; $20: e 0103$. https://doi.org/10.1590/pboci.2020.166

\begin{abstract}
Objective: To assess the knowledge level of parents from the central region of Saudi Arabia about oral health and care of preschool children and its relation with sociodemographic variables, parents' selfperception toward their dental health, importance of teeth, and frequency of dental visits. Material and Methods: A random sample of 754 parents participated in this cross-sectional study and completed an internationally accepted questionnaire. Chi-square test and logistic regression analysis were used to analyze the data $(\mathrm{p}<0.05)$. Results: Mean knowledge score of the parents was 4.8 (out of 11 ). Less than $20 \%$ of the parents were knowledgeable about the best position for tooth brushing, the concentration of fluoride in a child's toothpaste, timing of first dental check-up, and best time to give a sugary snack. Mothers, parents with high educational level and family income, parents with a positive attitude towards teeth and excellent self-perception of their dental health were significantly more likely to score higher $(p<0.05)$. Conclusion: Knowledge of parents about oral health and care of preschool children in the central region of Saudi Arabia was deficient. Gender, education level of parents, family income, attitude about teeth and self-perception of parents' own dental health were factors, which influenced their knowledge. To improve parents' knowledge, health professionals' role should be improved, and TV commercials directed toward the areas, which had gaps in knowledge.
\end{abstract}

Keywords: Child; Health Knowledge, Attitudes, Practice; Oral Health. 


\section{Introduction}

Early childhood caries (ECC) is a chronic transmissible infectious disease and multifactorial in nature. According to the American Academy of Pediatric Dentistry (AAPD), ECC is defined as the presence of one or more decayed, missing (due to caries), or filled tooth surface in any primary tooth in a child 6 years old or younger. At a very young age (three years of age and younger), any sign of smooth-surface caries constitutes severe ECC [1].

Without treatment, ECC can progress rapidly, causing pain and dental infection with a major impact on the quality of life and the ability to function in affected children [2-6]. Health care costs will also increase as dental treatment under general anesthesia may become required among the severe untreated cases and uncooperative children. Having children hospitalized because of ECC is very common, especially in developing countries [2-5]. Several studies have evaluated and categorized the risk factors of ECC, such as sociodemographic factors, dietary factors, oral hygiene factors, and factors related to oral bacterial flora as well as breast and bottle feeding [7].

As many of these risk factors can be prevented and require modification at the home level, parents' engagement, who are the legal guardians of children, particularly at a very young age, has been encouraged to facilitate preventive measures [8,9]. Parental perceptions about their children's oral health can affect the preventive dental care children receive at home and their use of professional dental services [10]. Hence, knowledge of parents regarding dietary recommendations, oral hygiene best practices as well as early establishment of a dental home for preschool children is crucial to reduce the burden of ECC [1,11]. Lack of parents' knowledge of oral health care for preschool children has been linked with an increase in ECC risk in their children [12].

In Saudi Arabia, ECC is a prevalent condition among preschool children. Prevalence estimates ranging from 27.3-73\% were reported in different regions of the country [13-15]. Previous reports have demonstrated insufficient knowledge of parents regarding oral health care best practices for their children $[16,17]$. Identifying areas with gaps in knowledge is important to direct education programs toward them and get them improved.

Therefore, the objective of this study was to assess the knowledge level of parents from the central region of Saudi Arabia about oral health and care of preschool children and its relation with sociodemographic variables, parents' self-perception toward their own dental health, as well as importance of teeth and frequency of dental visits.

\section{Material and Methods}

Ethical Approval

Ethical approval was obtained from the Ethical Committee of College of Dentistry, Qassim University (Reference Number: F-2019-3002).

Study Population

This was a cross-sectional study conducted on a random sample of Saudi parents from the country's central region who were contacted through social networking sites (Facebook and Twitter). Parents were recruited from social networking sites as these are very popular in Saudi Arabia. The inclusion criteria for the study were: parents who were residing in the central region of Saudi Arabia as well as speak and understand the Arabic language, parents who had a healthy, with no chronic illness or congenital anomaly, preschool child 
in the age range 6 months- 6 years, parents who gave written consent to participate in the study, and parents who had an account on Facebook or Twitter.

A sample size calculation was undertaken using the web site

http://www.raosoft.com/samplesize.html. A 5\% margin of error was selected, along with a 95\% confidence interval and 50\% response distribution. The calculated sample size was 377 parents; however, because it was difficult to ascertain whether that sample size would elicit sufficient responses from all parents (fathers and mothers), it was aimed to recruit at least double the number to achieve a representative sample.

\section{Study Measures}

Parents were sent a structured electronic questionnaire in the Arabic language in the period of October 2019 to March 2020. The Google form platform was used because it is available with no requirement for the parents to register [16]. The questionnaire was written initially in the English language, and it was a slight modification from a questionnaire previously adopted [10]. The questionnaire was then translated into the Arabic language and then back in the English language to ensure accuracy. English and Arabic versions were validated by two independent investigators to ensure the similarity of the content of both versions. The questionnaire consisted of three parts and aimed to assess: (1) sociodemographic profile of the parents, (2) selfperception of the parents' own dental health, importance of teeth and frequency of dental visits, and (3) parents' knowledge on oral health and care of preschool children.

\section{Data Analysis}

Statistical analysis of the data was conducted using the SPSS software, version 22.0 (SPSS Inc., Chicago, IL, USA). Percentages of parents' responses toward the questions, which assessed their sociodemographic profile, self-perception toward their overall dental health, importance of teeth and frequency of dental visits, and their knowledge about oral health and care of preschool children, were produced. Chisquare test was used to determine the relationship between the individual knowledge questions and the sociodemographic characteristics of the parents as well as the relationship between the questions, which assessed the parents' self-perception of their own dental health, importance of teeth, and frequency of dental visits with their sociodemographic characteristics. Parents were given a knowledge score, which ranged from 0 to 11 according to their answers on the knowledge questions. Every correct answer equaled one point. Mean knowledge scores were computed, and ordinal logistic regression analysis was used to ascertain the association of parents' sociodemographic profile, self-perception of their own dental health, and importance of teeth and dental visits with their mean knowledge score. The level of significance was set at $\mathrm{p}<0.05$ throughout.

\section{Results}

A total of 754 questionnaires were shared with the parents through Facebook and Twitter. A total of 192 questionnaires were not answered completely; consequently, they were excluded. The overall response rate was $74.5 \%$. The final sample was 562 parents who answered questionnaires for 562 preschool children.

Description of parents' sociodemographic background, as well as their self-perception towards their own overall dental health, importance of teeth and frequency of dental visits are summarized in Figures 1 and 2, respectively. At the same time, Table 1 shows the percentages of parents' responses in the questions which assessed their knowledge of oral health and care of preschool children. 


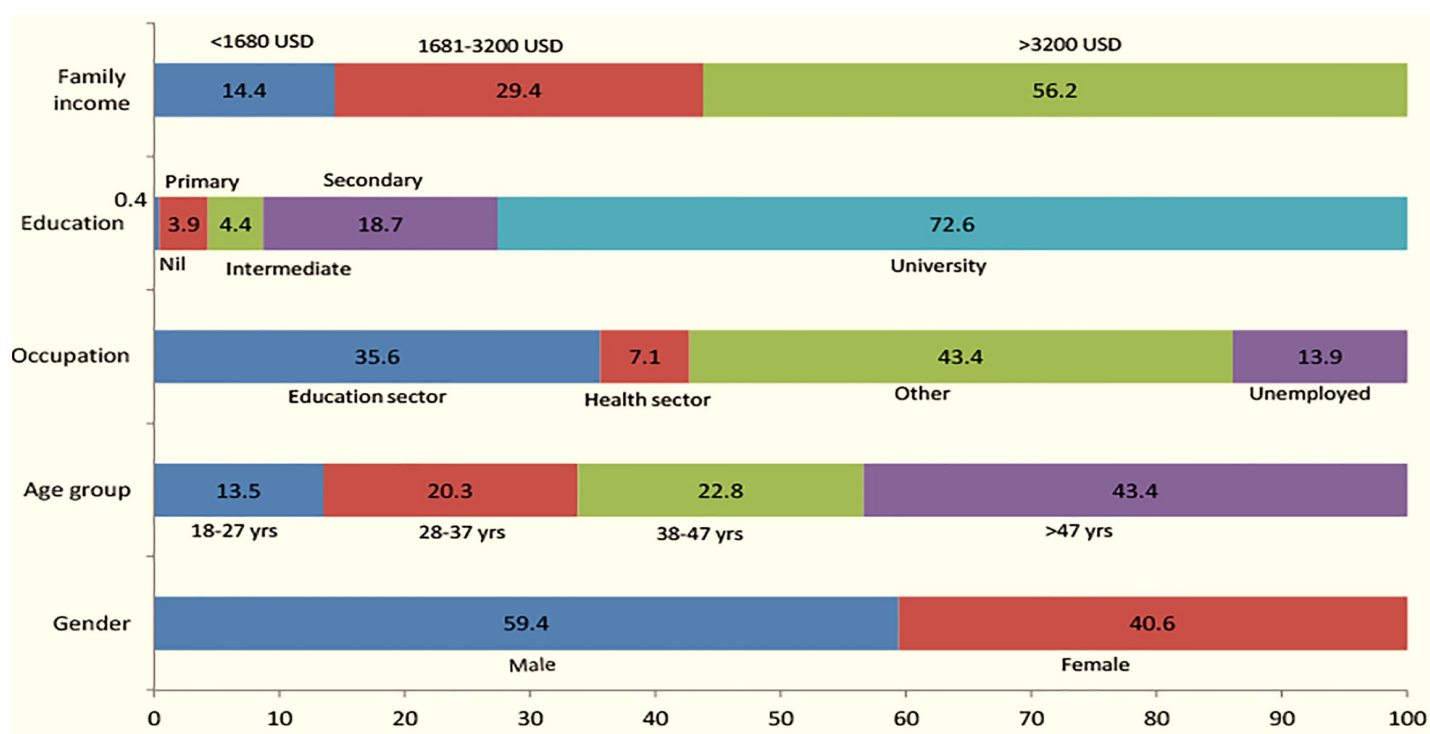

Figure 1. Parents' sociodemographic characteristics.

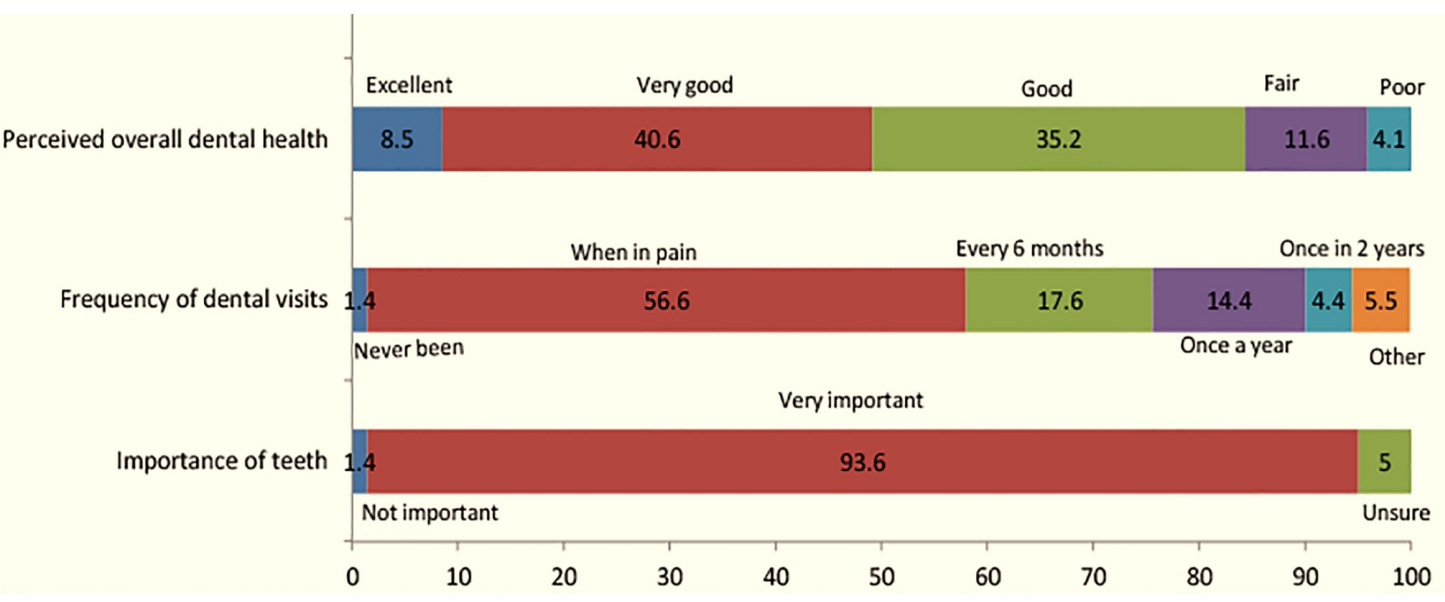

Figure 2. Parents' self-perception about their overall dental health, importance of teeth and frequency of dental visits.

Just less than half of the parents $(48.6 \%)$ identified the correct answer regarding optimum frequency of oral hygiene measures "twice daily". Significantly more mothers answered that question correctly when compared to fathers $(\mathrm{p}=0.014)$. More than two-thirds of the parents $(66.0 \%)$ identified the correct answer with regards to optimum size of toothbrush for their child "small", as well as thought that decay of primary teeth was "very important" (65.5\%).

Significantly more parents with a university degree answered the former question correctly, while significantly more mothers answered correctly the latter question $(\mathrm{p}=0.005$ and 0.001 , respectively). Little more than half of the parents $(55.5 \%)$ knew that fluoride should be present in a child's toothpaste. Significantly more fathers and parents with a university degree as well as parents with high monthly income answered correctly that question ( $\mathrm{p}=0.046,0.018$, and $<0.001$ respectively).

A majority of parents $(75.1 \%)$ answered correctly that children should not use a sweetened baby bottle or honey-dipped pacifiers and that decayed baby teeth should be filled (71.7\%). Significantly more mothers and parents working in education sector correctly answered the former question $(\mathrm{p}<0.001$ and 0.003 , respectively), whereas significantly more mothers, as well as parents with intermediate education level, and parents with high monthly income answered correctly the latter question ( $\mathrm{p}<0.001,0.013$, and 0.002, respectively). 
A minority of parents (4.6\%) knew optimum fluoride concentration in a child's toothpaste "1000 ppm" as well as optimum position while brushing a child's teeth "behind the child" (16.9\%), timing of the first dental check-up "on getting the first baby tooth" (14.4\%), and best time to give a child a sugary snack "during mealtimes" (16.5\%). Significantly more fathers and parents with secondary education level answered correctly the question about optimum fluoride concentration in a child's toothpaste $(\mathrm{p}=0.046$ and 0.018 respectively), while significantly more mothers answered correctly the question about the best time to give a child a sugary snack $(\mathrm{p}=0.037)$. Regarding part two questions, significantly more mothers self-perceived their own dental health as "Excellent" compared to fathers $(p=0.007)$.

Table 1. Parents' responses in the questions which assessed their knowledge of oral health and care of preschool children.

\begin{tabular}{|c|c|c|}
\hline Questions & Categories & $\mathbf{N}(\%)$ \\
\hline \multirow[t]{3}{*}{ Frequency of daily tooth brushing } & Once & $173(30.8)$ \\
\hline & Twice & $273(48.6)$ \\
\hline & Trice & $116(20.6)$ \\
\hline \multirow[t]{3}{*}{ Size of brush best for your child } & Small & $371(66.0)$ \\
\hline & Medium & $187(33.3)$ \\
\hline & Large & $4(0.7)$ \\
\hline \multirow[t]{4}{*}{ Quantity of tooth paste for your child } & Enough to cover whole head & $100(17.8)$ \\
\hline & Cover half head & $189(33.6)$ \\
\hline & Smear to pea size & $237(42.2)$ \\
\hline & Don't know & $36(6.4)$ \\
\hline \multirow[t]{4}{*}{ Optimum position to brush your child's teeth } & Front of the child & $153(27.2)$ \\
\hline & Behind the child & $95(16.9)$ \\
\hline & By side of the child & $186(33.1)$ \\
\hline & Don't know & $128(22.8)$ \\
\hline \multirow[t]{3}{*}{ Presence of fluoride in toothpaste } & Yes & $312(55.5)$ \\
\hline & No & $64(11.4)$ \\
\hline & Don't know & $186(33.1)$ \\
\hline \multirow[t]{4}{*}{ Fluoride content of child's toothpaste } & $1,000 \mathrm{ppm}$ & $26(4.6)$ \\
\hline & $1,500 \mathrm{ppm}$ & $12(2.1)$ \\
\hline & $500 \mathrm{ppm}$ & $50(8.9)$ \\
\hline & Don't know & $474(84.3)$ \\
\hline \multirow[t]{5}{*}{ Best time to give a child sugary snacks } & In the morning & $273(48.6)$ \\
\hline & At night & $30(5.3)$ \\
\hline & At meal-times & $93(16.5)$ \\
\hline & Any time & $103(18.3)$ \\
\hline & Don't know & $63(11.2)$ \\
\hline \multirow[t]{3}{*}{ Using sweetened baby bottle or honey-dipped pacifier is okay } & Yes & $23(4.1)$ \\
\hline & No & $422(75.1)$ \\
\hline & Don't know & $117(20.8)$ \\
\hline \multirow[t]{4}{*}{ Importance of decay in baby teeth } & Not at all important & $52(9.3)$ \\
\hline & Some of it important & $62(11.0)$ \\
\hline & Very important & $368(65.5)$ \\
\hline & Don't know & $80(14.2)$ \\
\hline \multirow[t]{4}{*}{ Optimum time of a child's first dental visit } & On getting first baby teeth & $81(14.4)$ \\
\hline & On having all baby teeth & $138(24.6)$ \\
\hline & When they get some baby teeth & $96(17.1)$ \\
\hline & Don't know & $247(44.0)$ \\
\hline \multirow[t]{4}{*}{ Treatment of decayed baby teeth } & Leave it alone & $18(3.2)$ \\
\hline & Fill it & $403(71.1)$ \\
\hline & Extract & $60(10.7)$ \\
\hline & Don't know & $81(14.4)$ \\
\hline
\end{tabular}

The results of ordinal logistic regression analysis and the factors, which had an association with the knowledge score of the parents are shown in Table 2. The mean knowledge score of the parents in the 
knowledge questions (part three questions) was 4.8 (out of $11 ; \pm 1.57$ ), the mean knowledge score of fathers was $4.48( \pm 1.54)$ while it was $5.2( \pm 1.50)$ for mothers.

According to the regression model, five factors had a statistically significant effect on the mean knowledge score of the parents; their gender and education level $(\mathrm{p}<0.001$ and $\mathrm{p}=0.024$, respectively), the family monthly income $(\mathrm{p}=0.026)$, parents' self-perception about the importance of teeth $(\mathrm{p}=0.03)$, as well as self-perception of their own dental health $(\mathrm{p}=0.007)$. Mothers had 2.2 (95\% confidence interval [CI $]$ : 0.315 0.651) times higher odds to score higher than fathers. Parents who had a university degree had 29.4 times (CI: 0.002-0.635) higher odds to score higher than parents who had never been to school. Parents who had a family monthly income $>3200$ USD had 1.52 times (CI: 0.457-0.950) higher odds to score higher than parents who had a family monthly income in the range 1681-3200 USD. On the other hand, parents who answered that their teeth were very important to them had 2.21 times (CI: 1.082-4.509) higher odds to score higher than parents who were not sure about their teeth. Finally, parents who rated their own overall dental health as "Excellent" had 3.71 times (CI: 1.436-9.564) higher odds to get a higher score than parents who rated their own dental health as "Poor".

Table 2. Variables associated with knowledge score of the parents.

\begin{tabular}{|c|c|c|c|c|c|c|}
\hline Variables & Category & $\begin{array}{c}\text { Mean Knowledge } \\
\text { Score }\end{array}$ & $\bar{B}$ & OR & $95 \% \mathrm{CI}$ & p-value \\
\hline \multirow[t]{2}{*}{ Gender } & Male & 4.48 & -0.792 & 0.453 & $0.315-0.651$ & $<0.001^{*}$ \\
\hline & Female Reference & 5.20 & $\mathrm{O}^{\mathrm{a}}$ & 1 & - & \\
\hline \multirow[t]{5}{*}{ Education } & Never Been to School & 2.0 & -3.393 & 0.034 & $0.002-0.635$ & $0.024 *$ \\
\hline & Primary & 4.78 & -0.628 & 0.534 & $0.242-1.174$ & 0.118 \\
\hline & Intermediate & 4.89 & 0.015 & 1.015 & $0.485-2.125$ & 0.968 \\
\hline & Secondary & 4.39 & -0.376 & 0.686 & $0.460-1.024$ & 0.065 \\
\hline & University Reference & 4.92 & $\mathrm{O}^{\mathrm{a}}$ & 1 & . & \\
\hline \multirow[t]{3}{*}{ Family Income } & $<1680$ USD & 4.61 & -0.157 & 0.855 & $0.526-1.391$ & 0.529 \\
\hline & 1681-3200 USD & 4.30 & -0.417 & 0.659 & $0.457-0.950$ & $0.026^{*}$ \\
\hline & >3200 USD Reference & 5.12 & $\mathrm{O}^{\mathrm{a}}$ & 1 & . & . \\
\hline \multirow[t]{3}{*}{ Importance of Teeth } & Not Important & 2.67 & -1.700 & 0.183 & $0.033-1.010$ & 0.051 \\
\hline & Very Important & 4.73 & 0.793 & 2.209 & $1.082-4.509$ & $0.030^{*}$ \\
\hline & Not Sure Reference & 3.57 & $\mathrm{O}^{\mathrm{a}}$ & 1 & . & . \\
\hline Perceived Overall & Excellent & 5.28 & 1.310 & 3.707 & $1.436-9.564$ & $0.007 *$ \\
\hline \multirow[t]{4}{*}{ Dental Health } & Very Good & 4.61 & 0.759 & 2.136 & $0.962-4.745$ & 0.062 \\
\hline & Good & 3.89 & 0.365 & 1.440 & $0.652-3.181$ & 0.367 \\
\hline & Fair & 4.06 & 0.119 & 1.127 & $0.472-2.688$ & 0.788 \\
\hline & Poor Reference & 3.01 & $\mathrm{O}^{\mathrm{a}}$ & 1 & . & . \\
\hline
\end{tabular}

*p<0.05; CI: Confidence Interval; OR: Odds Ratio.

\section{Discussion}

The results of the current study are disappointing as despite that relatively simple questions about oral health and care of preschool children were chosen, and that the majority of parents had positive attitude towards baby teeth and thought that baby teeth decay was important and should not be left but rather treated, the reported overall mean knowledge score of the parents was inadequate (4.8 out of 11).

Deficiencies in the knowledge of parents were noticed in the questions which covered issues related to oral hygiene practices (optimum frequency of tooth brushing per day, quantity of toothpaste suitable for preschool children, position of caregiver while brushing a child's teeth, and fluoride concentration in a child's toothpaste) as well as the questions about timing of first dental check-up and best time to give a child a sugary snack. The correct answer in these questions was given by less than half of the parents, more precisely less than fifth of the parents in the questions which concerned position of the caregiver while brushing a child's 
teeth, fluoride concentration in a child's toothpaste, timing of first dental check-up and best time to give a child a sugary snack. Previous authors also reported that parents performed poorly on questions to these effects [10]. In addition, current APPD recommendations about optimum timing of the first dental check-up and establishment of a dental home no later than one year of a child's age [19] seem up till now not communicated properly to the parents. Lack of parents' knowledge about optimum time of first dental check-up was repeatedly reported in Saudi Arabia as well as elsewhere [17,19-21]. More focus on education of parents about these issues is therefore required. Non-dental health professionals, particularly physicians and nurses, can be of great help in this regard. Optimum timing of the first dental check-up, for example, can be communicated to parents during well-child visits, which are mandatory for all preschool children after birth. It has been reported that physicians and nurses have the opportunity to provide oral care for preschool children seven times more frequently than dentists, especially those at high-risk for ECC as a result of well-child visits [22]. Interaction between members of the medical and dental communities is consequently crucial to help refer preschool children at high risk for ECC, especially those who do not have a dental home but have an established medical one [23,24]. Role of the media can also be enhanced to convey the message in an everyday basis to a huge audience; for example, TV commercials for toothpaste can include some information about the fluoride concentration and how to perform tooth brushing, as a demonstration, for a preschool child, as it is relatively difficult to expect parents to read that from tubes of toothpaste or to digest the information presented on dental health leaflets to improve their knowledge [25].

It has been reported that social, economic and environmental factors play a substantial role in shaping people's behavior and translating this knowledge into positive health choices and practices [26]. Socioeconomic status, which may be evaluated by income and education, was linked with dental caries in children; it has been reported that the higher the caregiver's educational level is, and the higher the family income is, the lower the child's caries experience is [21,26-28]. Improved level of education should lead to a better assessment of different sources of information about oral health and care and complete understanding, which should result in better knowledge from the part of the caregiver and consequently less caries experience in children [28,29]. This is supported in the current study, as parents who had the highest educational level (university degree) and those with the highest family income were significantly more knowledgeable. The current study also found that mothers were significantly more knowledgeable than fathers, which is quiet expected as mothers are the primary caregivers of their children. The same finding was reported by other authors [21]. Other factors, which were reported to positively affect the parents' knowledge score in the current study, included a positive attitude towards the importance of teeth and an "excellent" self-perception of parents' own dental health. Acknowledging the importance of teeth by parents is an important and encouraging thing. It implies that parents will likely respond more favorably toward oral health care information given to them from any health professional than parents who think that teeth are not important. On the other hand, caregiver's perceived level of own dental health in the current study had a significant impact on their actual knowledge of oral health and care for preschool children in a way that the better the parents perceived their own overall dental health, the higher their knowledge score was; particularly those who perceived their own dental health as "excellent" were significantly more likely to score higher.

Few limitations of the current study should be noted; the first limitation would be that the present study recruited parents from one region in Saudi Arabia; hence our results may not be generalized on all parents in the country, despite that different social, economic and educational diversities were included in the studied subpopulation. Another limitation would be that we did not ask the parents about the number of 
preschool children in their family; parents who take care of many preschool children are less likely to get free to read and improve their knowledge about oral health-related issues.

However, what should be kept in mind that the conclusion that there is a deficiency in the knowledge of the parents, regardless of the number of preschool children, would remain the same even after inclusion of parents who have many preschool children. The last limitation would be that more emphasis was made on knowledge of parents about oral hygiene practices when compared to dietary practices and breast and bottle feeding as it has been observed in several studies that parents' knowledge about dietary practices is generally better than oral hygiene practices, perhaps due to better reinforcement about dietary best practices for children in the media and local care setups [21,30].

\section{Conclusion}

Parents' knowledge about oral health and care of preschool children in the central region of Saudi Arabia was deficient, particularly in issues related to oral hygiene best practices, optimum timing of the first dental check-up, and best time to give a child a sugary snack. Mothers, parents with high educational level and family income (high social class), and parents who acknowledged the importance of teeth, as well as those who had excellent self-perception of their own dental health, were more knowledgeable. Improvement in parents' knowledge is possible by enhancing the role of other health professionals who more often communicate with parents and their preschool children when compared to dentists. TV dental commercials can also be enriched with information, which can fill the gap in parents' knowledge.

\section{Authors' Contributions}

SNA (D) 0000-0001-5210-5128 $\begin{aligned} & \text { Conceptualization, Methodology, Resources, Software, Supervision, Validation, } \\ & \text { Visualization, Writing - Review and Editing. } \\ & \text { Conceptualization, Data Curation, Investigation, Methodology, Project } \\ & \text { Administration, Writing - Original Draft. }\end{aligned}$
$\begin{aligned} & \text { All authors declare that they contributed to critical review of intellectual content and approval of the final version to be } \\ & \text { published. }\end{aligned}$

\section{Financial Support}

None.

\section{Conflict of Interest}

The authors declare no conflicts of interest.

\section{References}

[1] American Academy of Pediatric Dentistry. Policy on early childhood caries (ECC): Classifications, consequences, and preventive strategies. Pediatr Dent 2016; 38(6):52-4.

[2] Aldhilan S, Al-Haj Ali S. Approaches used to care for carious primary molars among pediatric dentists and general dental practitioners in Saudi Arabia. J Clin Exp Dent 2018; 10(3):e212-217. https://doi.org/10.4317/jced.54453

[3] Al-Ogayyel S, Al-Haj Ali S. Comparison of dental treatment performed under general anesthesia between healthy children and children with special health care needs in a hospital setting, Saudi Arabia. J Clin Exp Dent 2018; 10(10):e963-9.

[4] Avila WM, Pordeus IA, Paiva SM, Martins CC. Breast and bottle feeding as risk factors for dental caries: A systematic review and meta-analysis. PloS One 2015; 10(11):e0142922. https://doi.org/10.1371/journal.pone.0142922

[5] Özen B, Van Strijp AJP, Özer L, Olmus H, Genc A, Cehreli SB. Evaluation of possible associated factors for early childhood caries and severe early childhood caries: a multicenter cross-sectional survey. J Clin Pediatr Dent 2016; $4 \mathrm{O}(2): 118-23$. https://doi.org/10.17796/1053-4628-40.2.118 
[6] Buldur B, Güvendi ON. Conceptual modelling of the factors affecting oral health-related quality of life in children: A path analysis. Int J Paediatr Dent 2020; 30(2):181-92. https://doi.org/10.1111/ipd.12583

[7] Östberg AL, Skeie MS, Skaare AB, Espelid I. Caries increment in young children in Skaraborg, Sweden: associations with parental sociodemography, health habits, and attitudes. Int $J$ Paediatr Dent 2017; 27(1):47-55. https://doi.org/10.1111/ipd.12225

[8] American Academy of Pediatric Dentistry. Policy on early childhood caries (ECC): Unique challenges and treatment options. Pediatr Dent 2018; 40(6):63-4.

[9] Buldur B. Pathways between parental and individual determinants of dental caries and dental visit behaviours among children: Validation of a new conceptual model. Community Dent Oral Epidemiol 2020; 48(4):280-7. https://doi.org/10.1111/cdoe.12530

[10] Prabhu A, Rao AP, Reddy V, Ahamed SS, Muhammad S, Thayumanavan S. Parental knowledge of pre-school child oral health. J Community Health 2013; 38(5):880-4. https://doi.org/10.1007/s 10900-013-9693-x

[11] American Academy of Pediatric Dentistry. Policy on dietary recommendations for infants, children, and adolescents. Pediatr Dent 2018; 40(6):65-7.

[12] Naidu RS, Davis L. Parents' views on factors influencing the dental health of Trinidadian pre-school children. Community Dent Health 2008; 25(1):44-9.

[13] Wyne A, Darwish S, Adenubi J, Battata S, Khan N. The prevalence and pattern of nursing caries in Saudi preschool children. Int J Paediatr Dent 2001; 1 1(5):361-4. https://doi.org/10.1046/j.0960-7439.2001.00291.x

[14] Wyne AH, Al-Ghannam NA, Al-Shammery AR, Khan NB. Caries prevalence, severity and pattern in pre-school children. Saudi Med J 2002; 23(5):580-4.

[15] Al-Malik MI, Holt RD, Bedi R. Prevalence and patterns of caries, rampant caries, and oral health in two- to five-yearold children in Saudi Arabia. J Dent Child (Chic) 2003; 70(3):235-42.

[16] Alshehri A, Nasim VS. Infant oral health care knowledge and awareness among parents in Abha city of Aseer Region, Saudi Arabia. Saudi J Dent Research 2015; 6(2):98-101. https://doi.org/10.1016/j.sjdr.2015.01.001

[17] Al-Zahrani AM, Al-Mushayt AS, Otaibi MF, Wyne AH. Knowledge and attitude of Saudi mothers towards their preschool children's oral health. Pak J Med Sci 2014; 30(4):720-4. https://doi.org/10.12669/pjms.304.5069

[18] Alalawi A, Aljuaid H, Natto ZS. The effect of social media on the choice of dental patients: a cross-sectional study in the city of Jeddah, Saudi Arabia. Patient Prefer Adherence 2019; 13:1685-92. https://doi.org/10.2 147/ppa.s2 13704

[19] American Academy of Pediatric Dentistry. Definition of dental home. Pediatr Dent 2017; 39(6):12.

[20] Hamasha AAH, Rasheed SJ, Aldosari MM, Rajion Z. Parents knowledge and awareness of their children's oral health in Riyadh, Saudi Arabia. Open Dent J 2019; 13(1):236-41. https://doi.org/10.2174/1874210601913010236

[21] Ashkanani F, Al-Sane M. Knowledge, attitudes and practices of caregivers in relation to oral health of preschool children. Med Princ Pract 2013; 22(2):167-72. https://doi.org/10.1159/000341764

[22] Gonsalves WC, Skelton J, Heaton L, Smith T, Feretti G, Hardison JD. Family medicine residency directors' knowledge and attitudes about pediatric oral health education for residents. J Dent Educ 2005; 69(4):446-52.

[23] American Academy of Pediatric Dentistry. Policy on the dental home. Pediatr Dent 2017; 39(6):29-30.

[24] Al-Hatalani WY, Al-Haj Ali SN. Medical, dental, and nursing students' knowledge about early childhood oral health care. Children 2019; 6(9):97. https://doi.org/10.3390/children6090097

[25] Blinkhorn AS, Wainwright-Stringer YM, Holloway PJ. Dental health knowledge and attitudes of regularly attending mothers of high-risk, pre-school children. Int Dent J 2001; 51(6):435-8. https://doi.org/10.1002/j.1875595x.2001.tbo0856.x

[26] Cianetti S, Lombardo G, Lupatelli E, Rossi G, Abraha I, Pagano S, et al. Dental caries, parents educational level, family income and dental service attendance among children in Italy. Eur J Paediatr Dent 2017; 18(1):15-8. https://doi.org/10.23804/ejpd.2017.18.01.03

[27] Chan SCL, Tsai JSJ, King NM. Feeding and oral hygiene habits of preschool children in Hong Kong and their caregivers' dental knowledge and attitudes. Int J Paediatr Dent 2002; 12(5):322-31. https://doi.org/10.1046/j.1365263x.2002.00389.x

[28] Williams NJ, Whittle JG, Gatrell AC. The relationship between socio-demographic characteristics and dental health knowledge and attitudes of parents with young children. $\mathrm{Br}$ Dent J 2002; 193(11):651-4. https://doi.org/10.1038/sj.bdj.4801652

[29] Suresh BS, Ravishankar TL, Chaitra TR, Mohapatra AK, Gupta V. Mother's knowledge about pre-school child's oral health. J Indian Soc Pedod Prev Dent 2010; 28(4):282-7. https://doi.org/10.4103/0970-4388.76159

[30] Alshammary F, Aljohani FA, Alkhuwayr FS, Siddiqui AA. Measurement of parents' knowledge toward oral health of their children: an observational study from Hail, Saudi Arabia. J Contemp Dent Pract 2019; 20(7):801-5. 